\title{
Resenha: Ultrasociety. How 10,000 Years of War Made Humans the Greatest Cooperators on Earth
}

Para o biólogo Peter Turchin, as guerras foram mais importantes que a agricultura no desenvolvimento da cooperação entre seres humanos

TURCHIN, Peter (2016). Ultrasociety. How 10,000 years of war made humans the greatest cooperators on Earth. Chaplin: Beresta Books. 266 p. ISBN 10: 0996139516 - ISBN 13:

9780996139519

Piotr Tryjanowski

piotr.tryjanowski@gmail.com

Universidade de Ciências da Vida de Poznań, Polônia

Fabio Angeoletto fabio_angeoletto@yahoo.es

Universidade Federal de Mato Grosso, UFMT, campus de Rondonópolis, MT

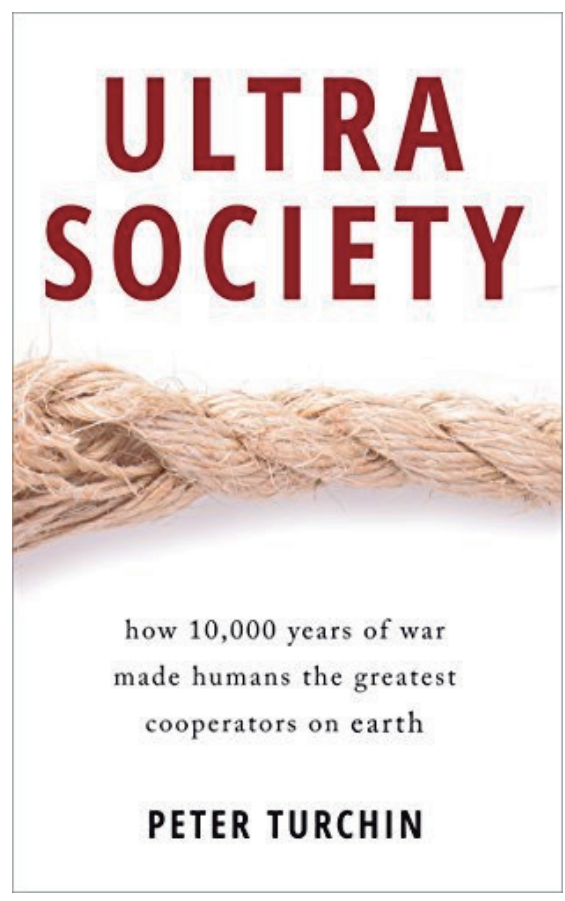

Da fome, do fogo e da guerra: salvai-nos, Senhor! Essa invocação vem sendo repetida há séculos. A humanidade sempre temeu guerras e turbulências, como fome e doenças, e esses infortúnios sempre caminharam muito próximos de nós. Nos interlúdios entre as guerras, nos preciosos períodos de paz, podemos tecer considerações sobre por que guerreamos. Milhares de obras, principalmente de sociólogos e historiadores, buscaram compreender 
quais são as causas desses conflitos sociais extremos. Por que em um átimo, após anos de convivência pacífica, começamos batalhas com paus, pedras, gládios, obuses e bombas atômicas? Por que às vezes é preciso tão pouca ignição para inflamar um conflito?

Pesquisadores das ciências sociais vêm buscando essas respostas com afinco, mas talvez não o façam adequadamente. Alguns críticos acreditam que, principalmente devido à falta de métodos quantitativos os cientistas sociais oferecem apenas respostas parciais a essas importantes questões. No entanto, empregando equações matemáticas avançadas da física teórica e da biologia populacional, é possível observar os processos históricos de maneira um pouco diferente. Estudiosos têm analisado quantitativamente a história, através de uma nova ciência, a cliodinâmica, cujo nome deriva de Clio, musa grega da História.

Um dos líderes da cliodinâmica é Peter Turchin, da Universidade de Connecticut. Turchin é um pensador original, que escreve com paixão e entusiasmo. Provavelmente existem tantos críticos dessa abordagem metodológica quanto apoiadores, mas sua originalidade é indiscutível. As questões fulcrais de Turchin são as seguintes: quão importantes as guerras foram no desenvolvimento da cooperação entre os humanos? Por que essa espécie belicosa é formada por grupos que não apenas batalham, mas também colaboram para a conquista da Terra, da Lua e das estrelas?

Evidentemente, o magnífico Império Romano não se constituía apenas de batalhas por territórios. Eles cooperavam com os vencidos para construírem aquedutos, estradas e cidades. Se saltarmos dois milênios, temos um nível de sofisticação cooperativa muito maior, para a exploração do espaço sideral. Como essa cooperação relaciona-se com as guerras? Para Turchin, a cooperação é filha da guerra.

Não foi a agricultura a matriz para o surgimento de grandes civilizações? Sim, esse é um evento que ganha importância a partir do exame histórico de eventos, personagens e locais. Sem embargo, o desenvolvimento da internet e a colaboração entre pesquisadores de várias especialidades, a possibilidade de combinar milhões de informações e de promover análises complexas de dados, fizeram com que muitas informações antes não conexas, oriundas de campos diversos como a arqueologia, a geografia, a agronomia, a economia, a demografia e até mesmo dados sobre batalhas pudessem finalmente ser reunidas. O livro Ultrasociety - How 10,000 years of war made humans the greatest cooperators on Earth é um resultado das análises feitas graças a essa abordagem de pesquisa conhecida como exploração de Big Data.

Peter Turchin anuncia uma premissa polêmica - as guerras foram mais importantes que a agricultura no desenvolvimento da cooperação entre seres humanos, porque elas têm consequências mais extensas, temporal e espacialmente. Viver juntos em zonas rurais ajuda a criar comunidades, indubitavelmente. Mas o que realmente as une é o enfrentamento conjunto de eventuais invasores - e a formação de coalizações com propósitos violentos é um fenômeno universal nas sociedades humanas (Brown, 1991; Angeoletto \& Silva, 2010). A luta por recursos - comida, água, prestígio, sexo, e acima de tudo, a luta pela vida geram e fortalecem a cooperação entre grupos de primatas humanos. Um vislumbre no mapa político do mundo mostra quão forte foi o fator guerra. Não é apenas a geografia física, e seus limites como rios ou cordilheiras, a responsável pelo arranjo das fronteiras 
dos Estados. Isso é mais frequentemente determinado pelas guerras e pelos tratados de paz que se seguem a elas.

Turchin argumenta que a guerra não é apenas uma época de esmagar crânios, trespassar vísceras ou lançar bombas e mísseis. Em primeiro lugar, suas consequências afetam quatro parâmetros importantes: população, estrutura social, força do estado (grupo) e instabilidade política. Os três primeiros fatores são obviamente simples de entender e são uma consequência direta das guerras. Por outro lado, a instabilidade política pode depor líderes e elites, e criar novas ordens sociais. É claro que existem ruínas e cinzas, e principalmente, cadáveres, mas essa força destrutiva terrível também pode ter um caráter criativo.

A destruição deixada pelo horrendo turbilhão das batalhas precisa ser reparada. Usualmente, após uma guerra, o entusiasmo é tão forte e o nível de cooperação entre as pessoas tão magnificado, que reconstruções são rapidamente impulsionadas. A cooperação desenvolvida ao longo do tempo não apenas fortalece pequenos grupos, mas também civilizações ou blocos políticos inteiros, que cobrem grande parte do globo. Pensemos novamente no Império Romano no seu apogeu e seus cinco milhões de quilômetros quadrados e 55 milhões de habitantes.

Viajemos novamente 20 séculos pelo tempo. Sem a cooperação da Guerra Fria entre os blocos comunista e capitalista, seu investimento em possibilidades técnicas para aniquilar o inimigo, e os avanços pacíficos derivados dessas técnicas, nós imaginaríamos voos tripulados para a Lua? Wernher von Braun, o engenheiro alemão que liderou o desenvolvimento dos foguetes V-2 na Alemanha nazista, também esteve à frente do projeto do Foguete Lunar Saturno V.

Mencionamos von Brau não para incensá-lo, mas para delinear as fronteiras infelizmente muito esgarçadas entre a loucura da destruição e o enlevo da cooperação. Esse forte vínculo criado entre colaboradores não apenas oferece a oportunidade da criação de novas tecnologias, mas, e isso também é muito importante, possibilita uma ligação social poderosa e duradoura. Grupos enormes, geralmente com dezenas de milhões de pessoas, baseados nos princípios de cooperação, são o que o professor Turchin chama originalmente de ultrassociedades.

Os historiadores tradicionais raramente concordam com as teorias cliodinistas. Com base em suas próprias pesquisas, eles geralmente enfatizam a singularidade dos eventos históricos, sua imprevisibilidade e o grande papel do acaso. Simplesmente deverá haver guerra em algum momento, mesmo que não a desejemos. Como reza o provérbio latino: Si vis pacem, para bellum - se queres a paz, prepara-te para a guerra. Os norte-americanos, sempre pragmáticos, dizem: Deus criou as pessoas, Samuel Colt tornou-as iguais.

A realidade sugere o óbvio - as guerras foram, são e serão. De acordo com Peter Turchin, o próximo grande conflito não deve tardar. Evidentemente, para um indivíduo, a guerra tem um significado diferente do que para uma nação. A guerra é mais perigosa para o indivíduo do que para a tribo, ainda que engajar-se em um conflito bélico pode ser socialmente bastante vantajoso aos beligerantes (nesse sentido, veja Pinker, 2018). Um fato paira acima de quaisquer controvérsias: as guerras revelam os covis mais abjetos da alma 
humana. No entanto, após anos de conflito, chega o momento de depor armas e cooperar. Até a próxima guerra?

\section{REFERÊNCIAS}

ANGEOLETTO, Fábio; SILVA, Natália M. (2010). Vacas Sagradas: os mitos nos discursos dos militantes ambientalistas. Travessias, 4(1), 357-370.

BROWN, Donald E. (1991). Human Universals. New York: McGraw-Hill.

PINKER, Steven (2018). Como a mente funciona. São Paulo: Companhia das Letras.

Data de submissão: 15/jun./2020

Data de aceite: 02/jul./2020 